\title{
Erratum to: Designing Systems with Adaptability in Mind
}

\author{
Haifeng Zhu
}

\section{Erratum to:}

Chapter 'Designing Systems with Adaptability in Mind' in: G. Auvray et al. (eds.), Complex Systems Design \& Management, DOI 10.1007/978-3-319-26109-6_20

Erratum DOI: 10.1007/978-3-319-26109-6_40

The spelling of the author name 'Haifeng Zlu' was incorrect. The name should read as Haifeng Zhu.

The updated original online version for this chapter can be found at DOI 10.1007/978-3-319-26109-6_20

\footnotetext{
H. Zhu ( $\square)$

United Technologies Research Center, East Hartford, USA

e-mail: ZhuHF@utrc.utc.com 